\title{
Neutrophil-Specific Antigen HNA-2a (NB1, CD177): Serology, Biochemistry, and Molecular Biology
}

\author{
David Stroncek, MD \\ The Department of Transfusion Medicine, Warren G. Magnuson Clinical Center, National Institutes of Health, Bethesda, Maryland
}

Human neutrophil antigen-2a (HNA-2a) is one of the most clinically important neutrophil alloantigens. It was previously known as NB1 (1). Monoclonal antibodies specific to HNA-2a have been clustered as CD177 (2). HNA2a was first described in 1971 in the sera of a women alloimmunized during pregnancy by Lalezari and collegues (3). HNA-2a specific antibodies cause alloimmune neonatal neutropenia, autoimmune neutropenia, and transfusionrelated acute lung injury. HNA-2a is expressed on neutrophils and neutrophilic metamyelocytes, and myelocytes from $89 \%$ to $97 \%$ of healthy individuals. It is a 56 to $64 \mathrm{kD}$ glycosylphosphatidylinositol (GPI) anchored plasma membrane glycoprotein (gp) that is also expressed on secondary granules. Among HNA-2a-positive people, the antigen is expressed on subpopulations of neutrophils. Approximately 55 to $65 \%$ of neutrophils in each healthy adult express HNA-2a. Four monoclonal antibodies specific to HNA-2a have been described 1B5, 7D8, MEM-166, and TAG4 (4-7). These antibodies have been useful in identifying the structure of the 56 to $64 \mathrm{kD}$ gp carring HNA-2a and in sequencing the gene encoding gp. The gene encoding HNA$2 \mathrm{a}$ is over expressed in people with polycythemia rubra vera, but the function of the CDI77 gp is not known.

\section{Expression of HNA-2a}

HNA-2a is neutrophil-specific. It is expressed on neutrophils, neutrophilic metamyelocytes, and myelocytes $(4,8)$. It is not expressed by other blood cells. HNA-2a is unique in that it is expressed on subpopulations of neutrophils. The mean size of the HNA-2a-positive subpopulation of neutrophils is $56 \%$ to $64 \%$ (5-9). Neutrohils tested from the same person at different times remains constant in regards to the percent of neutrophils expressing HNA-2a $(9,10)$. In approximately $8 \%$ of people three subpopulations of neutrophils can be detected, one not reactive with HNA-2a-specific antibodies and two that react with HNA-2a specific antibodies though with different intensities (10). The expression of HNA-2a is greater on neutrophils from women than men (10). The size of the HNA-2a positive subpopulation of neutrophils from women is $62 \pm 20 \%$ compared to $52 \pm 20 \%$ for men. The expression of HNA-2a falls with age in women, but remains constant in men (10). Neutrophil expression of HNA-2a is greater in pregnant women than in healthy female blood donors.

The administration of G-CSF to healthy subjects for several days increases the proportion of neutrophils expressing HNA-2a to near $90 \%$ (11). The surface expression of HNA-2a is slightly upregulated by treatment with the chemotactic peptide f-met-leu-phe $(9,12)$. The treatment of neutrophils with f-met-leu-phe does not change the percentage of cells that express HNA-2a (9).

\section{CD177 glycoprotein}

The glycoprotein carrying HNA-2a, CD177, is located on neutrophil plasma membranes and secondary granules (9, 13) and is linked to the plasma membrane via a glycosylphosphatidylinositol (GPI) anchor $(9,12)$. Although some GPI proteins are shed by f-met-leu-phe treated neutrophils, CD177 is not, nor is soluble CD177 present in plasma (9).

Sodium dodecyl sulfate-polyacrylamide gel electrophoresis (SDS-PAGE) analysis of CD177 after immunoprecipitation or immunoblotting shows a band of $\mathrm{Mr}$ of 56 to $64 \mathrm{kD}$ under reducing conditions and 49 to $55 \mathrm{kD}$ under non-reducing conditions $(9,13)$. In MALDI-TOF mass spectrometry, the purified glycoprotein has a molecular mass of $50.556 \mathrm{kD}(14,15)$. 
CD 177 has $N$-linked, but not $\mathrm{O}$-linked carbohydrate side chains (9, 13-15). Removal of $\mathrm{N}$-linked carbohydrates with endoglycosidase-F from immunoprecipated CD177 glycoprotein decreases the apparent molecular weight of the protein to approximately $45 \mathrm{kD}$ in $\operatorname{SDS}-\operatorname{PAGE}(9,13)$ and to 43.069 $\mathrm{kD}$ when determined by MALDI-TOF mass spectrometry $(14,15)$.

\section{Genomic Sequence}

The cDNA encoding the HNA-2a protein was found to consist of 1311 bp coding for a protein of 416 and a signal peptide of 21 amino acids $(14,15)$. The predicted protein has two cysteine-rich domains, threc potential $\mathrm{N}$-linked glycosylation sites, and a potential $w$-site for attachment of the GPI anchor $(14,15)$. This gene belongs to the Ly-6 snake toxin superfamily. Other genes in this family include urokinase type plasminogen activator receptor (UPAR) (CD87), decay acceralerating factor (CD59), and polycythemia rubra vera-1 $(P R V-I)$ gene. $P R V-l$ is over expressed in neutrophils from people with polycythemia rubra vera (16). The gene encoding HNA-2a and PRI-I differ at only $4 \mathrm{bp}$ (15). Bettinotti and colleagues used Human Genomic Project databases to characterize the structure of the $P R V-I$ and NBI genes (17). They described the intron and exon structure of NBI but they found only one gene homologous to both $P R V-I$ and NBI suggesting that they are alleles of the same gene. In addition. they found a pseudo gene homologous to exons 4 through 9 of PRII/NBl.

\section{CD177 Polymorphisms}

HNA-2a is expressed on neutrophils by approximately $97 \%$ of Caucasians, $95 \%$ of A frican Americans, and $89 \%$ to $99 \%$ of Japanese $(6,10,18,19,20)$. There is some variation in the expression of HNA-2a among antigen-positive people. When the expression of two HNA-2a-specific CDI77 monoclonal antibodies, 1B5 and 7D8, was compared the mean size of the subpopulation of neutrophils that reacted with these two antibodies was the same $(53.0 \pm 23.3 \%$ and $55.3 \pm 22.0 \%$, respectively), but the reactions of the two antibodies differed significantly in a few donors (10). In $10 \%$ of the donors the percentage of neutrophils that reacted with 1B5 and 7D8 differed by more than 12\% (10). These differences in the 1B5- and 7D8-subpopulation size occurred in $18 \%$ of Caucasian donors, but only in $4 \%$ of the African American donors (10). Two other HNA-2a specific CDI77 antibodies have been described, MEM-166 and TAG4. The two antibodies also recognized two subpopulations of neutrophils in most healthy adults and the size of the subpopulation of neutrophils recognized by MEM-166 and TAG4 is the same as that recognized by 7D8 (7).

HNA-2a has been reported to have an allele, NB2, but the product of this gene can not be reliably identified with alloantisera and no monoclonal antibody specific for NB2 has been identified (21-23). Rabbit polyclonal antibodies that react with CDI77 glycoprotein do not react with any glycoprotein on HNA-2a-negative neutrophils in flow cytometry. immunoblotting, or immunoprecipation assays (22).

HNA-2a genes from two women with HNA-2a-negative neutrophils who produced HNA-2a-specific alloantibodies have been studied and PRV-1/NBI cDNA sequences were present in both women (24). Their neutrophil mRNA was isolated, converted to cDNA and analyzed. PCR products of variable lengths were detected and sequencing detected both exons and accessory sequences that were considered to be introns. Some cDNAs containing the entire $P R V-1 / N B I$ coding sequence were identified, but all cDNA had some accessory sequences.

\section{Disease Relevance}

The expression of HNA-2a is reduced on neutrophils from people with paroxysmal nocturnal hemoglobinuria (PNH) and chronic myelogenous leukemia (CML) $(8,9)$. It is not known if the lack of expression of HNA-2a on neutrophils from patients with PNH or CML has any clinical significance. PRV-1/NBl mRNA is over expressed by neutrophils from patients with polycythemia rubra vera. The significance of this is not certain.

The $3 \%$ of people whose neutrophils lack HNA-2a are not at increased risk of infection or autoimmune disorders. However. HNA-2a-negative mothers with HNA-2a-positive neonates can produce HNA-2a-specific alloantibodies which can cause the neonate to experience neutropenia lasting several weeks (25-27). Transfusion of blood components containing alloantibodies specific for HNA-2a can cause severe transfusion-related acute lung injury (TRALI) in the transfused patients $(25,28)$. Antibodies specific for HNA-2a have also been produced by some patients with quinineinduced neutropenia (29).

Alloantibodies to HNA-2a can also be produced by patients transfused with granulocyte concentrates (30). When patients with HNA-2a specific alloantibodies are transfused with HNA-2a-positive granulocytes they can experience febrile transfusion reactions and shorten survival of the transfused granulocytes can occur.

\section{Role of CD177 in Cellular Function}

The role of $\mathrm{CD} 177$ in neutrophil function is unknown. In some studies, HNA-2a-positive neutrophils were significantly less adherent to human umbilical vein endothelial cells than HNA-2a-negative neutrophils (31). Upregulation of HNA-2a after f-met-leu-phe stimulation, HNA-2a internalization upon antibody cross-linking, and activation of the respiratory burst after binding of HNA-2a antibodies to HNA-2a-bearing neutrophils suggest a possible role as receptor molecule (32). 


\section{REFERENCES}

1. Bux J, Biering P. Bome AEGKr von dem et al. ISBT Granulocyte Antigen Workıng Party. Nomenclature of Granulocyte Alloantigens. Vox Sang 1999; 77:251.

2. Mason DY, Andre P, Bensussan A, Buckley C. Civin C. Clark E, de Haas M, Goyert S, Hadam M, Hart D, Horejsı V V, Meuer S, Morissey J, Schwartz-Albiez R. Shaw S, Simmons D, Uguccionı M, van DerSchoot E, Viver E, Zola H. CD antigens 2001. Tissue Antıgens. 2001,58:425-430.

3. Lalezari P, Murphy GB, Allen FH NB1, a new neutrophil antıgen involved in the pathogenesis of neonatal neutropenia. J Clin Invest 1971; 50: 1108-1115.

4. Clement LT, Lehmeyer JE, Gartland GL. Identification of neutrophil subpopulations with monoclonal antibodies. Blood 1983: 61; 326-332.

5. Stroncek DF, Shankar RA, Noren PA, Herr GP, Clement LT. Analysis of the expression of NB1 antıgen using two monoclonal antibodies. Transfusion 1996; 36: 168-174.

6. Tanıguchı K, Kıbayashi M, Harada H, Hiraoka H, Hıraoka A, Tanihim M. Takata $N$, Kımura A. Human neutrophil antigen-2a expression on Neutrophils from Healthy adults from Western Japan. Transfusion (in Press).

7. Canuccio L, Bettinotti M, Matsuo K, Sharon V, Stroncek D. Expression of Neutrophil-specific antigen HNA-2a (NBI) antigen increase Duming Pregnacy Transfusion

8. Stroncek DF, Shankar R, Litz C, Clement L. The expression of the NBl antigen on myelord precursors and neutrophils from children and umbilical cords Transfusion Medicine 1998; 8: 119-123.

9. Goldschmeding R, van Dalen, CM, Faber N, Calafat J, Huizinga TWJ, van der Schoot CE, Clement LT, von dem Borne AEG Kr. Further characterization of the NB1 antigen as a vanably expressed 56-62 kD GPI linked glycoprotein of plasma membranes and specific granules of neutrophils. Br J Haematol 1992; 81: 336 345.

10. Matsuo K, Lin A, Procter J, Clement L, Stroncek DF Variations in the expression of granulocyte antigen NBI. Transfusion 2000; 40; 654-662.

11. Stroncek DF, Jaszcz W, Herr G, Clay ME, McCullough J. Expression of neutrophil antigens after 10 days of granulocyte colony-stimulating factor. Transfusion 1998; 38: 663-668.

12. Skubıtz KM, Stroncek DF, Sun B. Neutrophil-specific antigen NB1 is anchored via a glycosyl-phosphatidylınositol linkage. J Leukoc Biol 1991; 49: 163-171.

13. Stroncek DF, Skubitz KM, McCullough J. Biochemical nature of the neutrophilspecific antigen NB1. Blood 1990; 75 744-755.

14. Bux J. Molecular Genetics of Granuiocyte Polymorphisms. Vox Sang 2000; 78 (suppl.2): 125-130

15. Kissel K, Santoso S, Hofmann C, Stroncek D, Bux, J. Molecular basis of the neutrophil glycoprotein NBI (CDI77) involved in the pathogenesis of immune neutropenias and transfusion reactions. European Journal of Immunology 2001;31: 1301-1309.

16. Temerinac S, Klippel S, Strunck E, Roder S, Lubbert M, Lange W, Azemar M, Meinhardt G, Schaefer HE, Pahl HL. Cloning of PRV-1, a novel member of the UPAR receptor superfamily, which is overexpressed in polycythemı rubra vera. Blood 2000; 95: 2569-2576.

17. Bettinotti MP, Olsen A, Stroncek D. The Use of Bioinformatics to Identify the Genomic Structure of the Gene that Encodes Neutrophll Antigen NB1, CD177. Clinical Immunology 2002;102:138-144.

18. Bierling P, Poulet E, Fromont P, Seror T, Bracq C, Duedari N. Neutrophil-specific antigen and gene frequencies in the French population (letter). Transfusion 1990; 30: 848-849.

19. Lin $M$, Chen CC, Wang CL, Lee HL. Frequencies of neutrophil-specific antigens among chınese in Taiwan (letter). Vox Sang 1994; 66: 247.

20. Ohto $\mathrm{H}$, Matsuo $Y$. Neutrophil-specific antigens and gene frequencies in the Japanese (Letter). Transfusion 1989; 29: 654.

21. Lalezari P, Petrosova M, J1ang AF. NB2, an allele of NB1 neutrophil specific antigen: relationship to 9a (Abstract). Transfusion 1982; 22: 433 .

22. Stroncek DF, Shankar RA, Plachta LB, Clay ME, Dalmasso AP. Polyclonal antibodies against NBI-bearing 58-64 kDa glycoprotein of human neutrophils do not identify an NB2-bearing molecule. Transfusion 1993; 33: 399-404

23. Bux J, Chapman J. Report on the Second International Granulocyte Serology Workshop. Transfusion 1997; 37: 977-983.

24. Bux J, Scheffler S, Kissel K. Molecular basis of the NBI (HNA-2a)-negative phenotype. Blood 2000; 96; 656a.

25. Bux J. Granulocyte antibody-medjated neutropenias and transfusion reactions. Infusionsther Transfusionsmed 1999; 26:152-157.

26. Clay ME, Stroncek DF. Granulocyte Immunology. In: Ness $P$, Anderson $K$, eds. Scientific Basis of Transfusion Medicine. Philadelphia, PA. WB Saunders Company. 1994: 244-280.

27. McCullough J, Clay M, Press C, Kline W. Granulocyte Serology: A Clinical Laboratory Guide, Chicago: ASCP Press, 1988.

28. Bux J, Becker F, Seeger W, Kilpatrick D, Chapman J, Waters A: Transfusionrelated acute lung injury due to HLA-A2-specific antibodies in reciptent and NB1-specific antibodies in donor blood. Br J Haematol 1996; 93: 707-713.
29. Stroncek DF, Shankar RA, Herr GP. Quinine-dependent antibodıes to neutrophils react with a $60 \mathrm{kD}$ glycoprotein on which NBl antigen is located and an $85 \mathrm{kD}$ gylcosylphosphatidylinositol linked $\mathrm{N}$-glycosylated plasma membrane glycoprotein. Blood 1993; 81· 2758-2766.

30. Suroncek DF, Leonard K, Eiber G, Malech HL, Gallin JI, Leitman SF. Alloımmunization following granulocyte transfusıons. Transfuston 1996; 36 10019-1015.

31. Stroncek DF, Hert GP, Plachta LB. Neutrophıl-specific antigen NB1 inhibıts neutrophil-endothelıal cell interactions. J Lab Clin Med 1994, 123: 247-255.

32. Bux J, Dickmann JO. Stockert U. Mueller-Eckharde C. Influence of granulocyte antibodies on granulocyte function. Vox Sang 1993; 64: 220-225 